AperTO - Archivio Istituzionale Open Access dell'Università di Torino

\title{
JAK2V617F activating mutation is associated with the myeloproliferative type of chronic myelomonocytic leukaemia
}

\section{This is the author's manuscript}

Original Citation:

\section{Availability:}

This version is available http://hdl.handle.net/2318/61942

since

Terms of use:

Open Access

Anyone can freely access the full text of works made available as "Open Access". Works made available under a Creative Commons license can be used according to the terms and conditions of said license. Use of all other works requires consent of the right holder (author or publisher) if not exempted from copyright protection by the applicable law. 


\section{JAK2V617F activating mutation is associated with the myeloproliferative type of chronic myelomonocytic leukaemia}

A Pich, L Riera, F Sismondi, et al.

J Clin Pathol 2009 62: 798-801

doi: 10.1136/jcp.2009.065904

Updated information and services can be found at:

http://jcp.bmj.com/content/62/9/798.full.html

\section{These include:}

References This article cites 15 articles, 6 of which can be accessed free at: http://jcp.bmj.com/content/62/9/798.full.html\#ref-list-1

Email alerting Receive free email alerts when new articles cite this article. Sign up in the service box at the top right corner of the online article.

Topic collections Articles on similar topics can be found in the following collections

Molecular genetics (2002 articles)

Immunology (including allergy) (43767 articles)

Clinical diagnostic tests (18740 articles)

Notes

To order reprints of this article go to:

http://jcp.bmj.com/cgi/reprintform

To subscribe to Journal of Clinical Pathology go to:

http://jcp.bmj.com/subscriptions 


\title{
JAK2 ${ }^{\mathrm{V} 617 \mathrm{~F}}$ activating mutation is associated with the myeloproliferative type of chronic myelomonocytic leukaemia
}

\author{
A Pich, ${ }^{1}$ L Riera, ${ }^{2}$ F Sismondi, ${ }^{2}$ L Godio, ${ }^{1}$ L Davico Bonino, ${ }^{1}$ F Marmont, ${ }^{3}$ P Francia di Celle ${ }^{2}$
}

\begin{abstract}
${ }^{1}$ Department of Biomedical Sciences and Human Oncology, Section of Pathology, University of Turin, Turin, Italy; ${ }^{2}$ Center for Experimental Research and Medical Studies (CERMS), Turin, Italy; ${ }^{3}$ Division of Haematology, San Giovanni Hospital, Turin, Italy

Correspondence to: Professor Achille Pich, Department of Biomedical Sciences and Human Oncology, Section of Pathology, University of Turin, Via Santena 7, I-10126 Torino, Italy;

achille.pich@unito.it
\end{abstract}

Accepted 18 May 2009

\begin{abstract}
Background: Chronic myelomonocytic leukaemia (CMML) is a haematopoietic malignancy with heterogeneous clinical and morphological features. It is classified in the World Health Organization myeloproliferativemyelodysplastic overlap category. JAK2 ${ }^{\mathrm{V} 617 \mathrm{~F}}$ mutation can be found in a large percentage of patients with myeloproliferative neoplasms.
\end{abstract}

Aims: To investigate the association between JAK2 ${ }^{\mathrm{V} 617 \mathrm{~F}}$ mutation and clinical, haematological and bone marrow histological features in CMML and to verify whether the mutation is associated with the myeloproliferative type of the disease.

Methods: 78 consecutive patients with newly diagnosed CMML from 2004 to 2008 were included in the study. JAK2 ${ }^{\mathrm{V} 617 \mathrm{~F}}$ mutation was assessed using direct sequencing of exon 14 or by allele-specific PCR from total peripheral blood or bone marrow samples.

Results: JAK2 ${ }^{\mathrm{V} 617 \mathrm{~F}}$ mutation was identified in eight cases $(10.2 \%)$. All patients with the mutation presented with splenomegaly and had a significantly higher haemoglobin level and neutrophil count than patients without the mutation. All bone marrow biopsies of JAK2 ${ }^{\mathrm{V} 617 F}$-mutated CMML showed increased erythropoiesis, a marked myeloid and megakaryocytic hyperplasia with occasionally clustered megakaryocytes, and a mild or moderate (grade 1 or 2) fibrosis; six cases showed an increased number of dilated sinusoids and reactive lymphoid nodules.

Conclusions: The results indicate that JAK2 ${ }^{\mathrm{V} 617 \mathrm{~F}}$ mutation is associated with clinical and morphological features of the myeloproliferative type of CMML. Therefore, JAK2 mutation analysis together with bone marrow morphology could help in a more appropriate classification of the disease.

Chronic myelomonocytic leukaemia (CMML) is a clonal disorder of a bone marrow stem cell, characterised by a persistent peripheral blood monocytosis. The clinical, haematological and morphological features of the disease are heterogeneous and vary from predominantly myelodysplastic to mainly myeloproliferative patterns. ${ }^{1-3}$ According to the World Health Organization (WHO) classification of myeloid neoplasias, CMML is placed in the myeloproliferative-myelodysplastic overlap category. ${ }^{4}$ However, a more appropriate classification of the disease would be desirable.

A somatic point mutation (V617F) in a highly conserved residue of the pseudokinase domain of the Janus kinase 2 (JAK2) has been detected in a large percentage of patients with myeloproliferative disorders, such as polycythaemia vera (65-97\%), essential thrombocythaemia (23-79\%) and primary myelofibrosis (35-78\%)..$^{5-9} \mathrm{JAK} 2^{\mathrm{V} 617 \mathrm{~F}}$ mutation has been rarely observed in patients with myelodysplastic/myeloproliferative diseases or myelodysplastic syndromes. ${ }^{10-12}$

The aim of this study was to search for JAK2 $2^{\mathrm{V} 617 \mathrm{~F}}$ mutation in CMML and investigate the relationship with clinical, haematological and bone marrow (BM) histological features, to verify whether the JAK2 $2^{\mathrm{V} 617 \mathrm{~F}}$ mutation is associated with the myeloproliferative type of CMML.

\section{METHODS}

\section{Patients}

A total of 78 consecutive patients with newly diagnosed CMML, admitted to the Division of Haematology, San Giovanni Hospital and University of Turin, Italy, from 2004 to 2008 were included in the study. Diagnosis of CMML was performed according to WHO criteria. ${ }^{4}$ There were 24 women and 54 men; the mean age was 70 years (range 36-88 years). The study was carried out with the approval of the local ethics committee. BM biopsies were taken during initial investigation, from posterior-superior iliac crest, using a Jamshidi needle.

\section{Histology}

Specimens were immediately fixed in buffered acid formol for $24 \mathrm{~h}$, decalcified in Osteodec (EDTA, $\mathrm{HCl}$ mixture; Bioptica, Milan, Italy) for $6 \mathrm{~h}$, dehydrated, and embedded in paraffin. Serial sections ( $3 \mu \mathrm{m}$ thick) were stained with $\mathrm{H} \& \mathrm{E}$, Dominici, Perls and Gomori stains. Immunohistochemistry was performed with an automatic stainer device (Dakoautostainer; Dako, Glostrup, Denmark), using the Labelled Streptavidin-Biotin 2 System detection kit (Dako), diaminobenzidine as a chromogen, and the monoclonal antibodies anti-CD34 (Clone OBEnd/10), anti-CD31 (clone JC70A), anti-von Willebrand Factor (Clone F8/86), anti-glycophorin A (Clone JC159), anti-CD68 (clone PG-M1), and the polyclonal antibody anti-human myeloperoxidase (all from Dako, Glostrup, Denmark). The following histological parameters were evaluated: marrow cellularity, hyperplasia and dysplasia of the erythroid, myeloid and megakaryocyte lineages, percentage of monocytes and CD34positive blasts, marrow fibrosis, presence of dilated sinusoids and reactive lymphoid nodules. Bone marrow cellularity was determined taking into account the age-related changes in the study population. ${ }^{13}$ The different cell lineages were 
semiquantitatively evaluated by a score that was mainly based on their frequency in the normal $\mathrm{BM}:{ }^{14} 0$, no increase in comparison with the normal state; +1 , mild increase (corresponding to a mild hyperplasia); +2 , moderate increase (moderate hyperplasia); +3 , marked increase (marked hyperplasia). BM fibrosis was graded according to the criteria of the European consensus on grading bone marrow fibrosis ${ }^{13}$ and a semiquantitative scale was used: 0 , scattered linear reticulin with no intersections, corresponding to normal bone marrow; 1 , loose network of reticulin with many intersections, especially in perivascular areas (corresponding to a mild fibrosis); 2, diffuse and dense increase in reticulin with extensive intersections, occasionally with only focal bundles of collagen (corresponding to a moderate fibrosis). All biopsy specimens were independently examined by two pathologists (AP, LG) who had no knowledge of the mutational status. Disagreement between the observers was found in less than $10 \%$ of the cases. In these cases, a consensus interpretation was reached after re-examination of the slides with a double-headed microscope.

\section{JAK2 ${ }^{\mathrm{V} 617 \mathrm{~F}}$ mutation analysis}

JAK2 ${ }^{\mathrm{V} 617 \mathrm{~F}}$ mutation testing was performed on peripheral blood or bone marrow samples. RNA and/or DNA were automatically extracted by using Maxwell 16 blood DNA purification kit, Wizard SV 96 genomic DNA purification system or SV96 total RNA isolation system following the manufacturer's instructions (Promega Corporation, Madison, Wisconsin, USA). cDNA was prepared by reverse transcription following the standardised BIOMED-1 protocol. ${ }^{15} \mathrm{JAK} 2^{\mathrm{V} 617 \mathrm{~F}}$ mutation was assessed in all cases using direct sequencing of exon 14 cRNA: PCR primers (forward: 5'-GTAGGAGACTACGGTCAACTG-3'; reverse: 5'TGCATGGCCCATGCCAACT-3') were designed to amplify a $273 \mathrm{bp}$ segment of JAK2 encompassing the codon for amino acid 617. The sequencing reaction was carried out using the Big Dye Terminator Cycle Sequencing Ready Reaction Kit (Applied Biosystems, Foster City, California, USA), and the analysis was performed on an ABI 310 automated capillary system, following the manufacturer's instructions. All sequences of samples were compared with published germ-line sequences using basic local alignment search tool (BLAST) on the Internet.

In selected cases, allele-specific PCR was also utilised to screen for the JAK2 ${ }^{\mathrm{V} 617 \mathrm{~F}}$ point mutation on DNA by amplifying JAK2 exon $14 .^{5}$

\section{Statistical analysis}

The independence between categorical variables and JAK2 ${ }^{\mathrm{V} 617 \mathrm{~F}}$ status was estimated by the Fisher's exact test. Continuous variables were compared by the Mann-Whitney U test. All data were processed with $\mathrm{BMDP}$ selected programs $(2 \mathrm{D}, 3 \mathrm{D}, 7 \mathrm{D}$, $4 \mathrm{~F}) .{ }^{16}$

\section{RESULTS}

JAK2 ${ }^{\mathrm{V} 617 \mathrm{~F}}$ mutation was identified in 8 of 78 cases $(10.2 \%)$. The results of the association between JAK2 ${ }^{\mathrm{V} 617 \mathrm{~F}}$ mutation and clinical, haematological and BM histological features in patients with CMML are summarised in tables 1 and 2. Of 37 patients that had palpable splenomegaly, 22 underwent an ultrasound or CT scan that showed a maximum diameter of the spleen ranging from 14 to $25 \mathrm{~cm}$. All patients with JAK2 ${ }^{\mathrm{V} 617 \mathrm{~F}}$ mutation presented with splenomegaly (palpable spleen or echographically/CT enlarged spleen more than $14 \mathrm{~cm}$ in the maximum diameter), while splenomegaly was found in only 29 of 70 JAK2 $2^{\mathrm{V} 617 \mathrm{~F}}$-negative patients $(p=0.001)$. Patients with JAK2 ${ }^{\mathrm{V} 617 \mathrm{H}}$
Table 1 Association between JAK2 ${ }^{\mathrm{V} 617 \mathrm{~F}}$ mutation and clinical and haematological features in chronic myelomonocytic leukaemia $(n=78)$

\begin{tabular}{lccl}
\hline Variable & $\begin{array}{l}\text { JAK2 } \\
(\mathbf{n}=\mathbf{8})\end{array}$ & $\begin{array}{l}\text { J617F } \\
(\mathbf{n}=\mathbf{7 0})\end{array}$ & p Value \\
\hline Age, years & $68.9(8.3)$ & $70.2(10.9)$ & 0.4 \\
Haemoglobin, g/dl & $13.1(2.7)$ & $10.8(2.2)$ & 0.02 \\
WBC count, $\times 10^{9} / 1$ & $28.386(29.77)$ & $18.039(19.73)$ & 0.1 \\
Platelets, $\times 10^{9} / 1$ & $205.5(277)$ & $139.1(141)$ & 0.6 \\
Neutrophils, $\times 10^{9} / 1$ & $22.624(27.33)$ & $8.267(8.62)$ & 0.02 \\
Lymphocytes, & $2.435(1.047)$ & $3.230(4.910)$ & 0.5 \\
$\times 10^{9} / l$ & & & \\
Monocytes, $\times 10^{9} / 1$ & $2.890(2.382)$ & $3.631(4.653)$ & 0.8 \\
Splenomegaly, & $8(100)$ & $29(41.4)$ & 0.001
\end{tabular}

n $(\%)$

Values are means (SD), unless otherwise indicated.

WBC, white blood cell.

mutation had also significantly higher red blood cell count $\left(4.747 \times 10^{12} / 1\right.$ versus $\left.3.593 \times 10^{12} / 1, p=0.01\right)$, haemoglobin level $(13.1 \mathrm{~g} / \mathrm{dl}$ versus $10.8 \mathrm{~g} / \mathrm{dl}, \mathrm{p}=0.02)$ and neutrophil count $\left(22.624 \times 10^{9} / 1\right.$ versus $\left.8.267 \times 10^{9} / 1, p=0.02\right)$ than patients without the mutation. No association was found for patient age, sex, white blood cell count, or platelet, monocyte or lymphocyte count. BM biopsies of CMML with JAK2 $2^{\mathrm{V} 617 \mathrm{~F}}$ mutation showed a mean cellularity of $85 \%$ (range $70-100$ ), a mean percentage of CD34-positive blasts of $5.75 \%$ (range 1-15) and a mean percentage of monocytes of $18.1 \%$ (range 15-25); these values were not different to BM biopsies of non-mutated cases. Erythroid hyperplasia was found in all mutated cases, but in only 20 of $70(28.6 \%)$ non-mutated cases $(p=0.0001)$. A marked myeloid (fig 1) and megakaryocytic hyperplasia was seen in all mutated cases, but in only $60 \%$ and $50 \%$ of non-mutated cases $(p=0.02$ and 0.006 , respectively). Megakaryocytes were occasionally clustered and large, with hyperlobulated nuclei (fig 1, inset). Mild or moderate fibrosis (grade 1 or 2$)^{13}$ (fig 2) was seen in all mutated cases, but in only 13 of $70(18.6 \%)$ non-mutated cases $(p<0.00001)$. An increased number of dilated sinusoids and reactive lymphoid nodules was seen in six of mutated cases $(75 \%)$, but in only $4(5.7 \%)$ and $15(21.4 \%)$ of non-mutated cases $(p<0.0001$ and 0.004 , respectively).

\section{DISCUSSION}

Our results show that JAK2 $2^{\mathrm{V} 617 \mathrm{~F}}$ mutation can be detected in a small number (8/78) of CMML, in accordance with previous

Table 2 Association between JAK2 ${ }^{\mathrm{V} 617 \mathrm{~F}}$ mutation and bone marrow histology in chronic myelomonocytic leukaemia $(n=78)$

\begin{tabular}{|c|c|c|c|}
\hline Variable & $\begin{array}{l}\text { JAK2 }{ }^{\text {V617F }} \\
\text { positive }(n=8)\end{array}$ & $\begin{array}{l}\text { JAK2 } \\
(n=70)\end{array}$ & p Value \\
\hline Cellularity* & $85(10.7)$ & $83.3(10.6)$ & 0.8 \\
\hline CD34+ blasts* & $5.75(5.2)$ & $3.04(3.46)$ & 0.09 \\
\hline Monocytes* & $18.1(3.72)$ & $19.5(8.2)$ & 0.9 \\
\hline Fibrosis, n (\%) & $8(100)$ & $13(18.6)$ & $<0.00001$ \\
\hline $\begin{array}{l}\text { Erythroid hyperplasia, } \\
\mathrm{n}(\%)\end{array}$ & $8(100)$ & $20(28.6)$ & 0.0001 \\
\hline $\begin{array}{l}\text { Myeloid hyperplasia, } \\
\text { n (\%) }\end{array}$ & $8(100)$ & $42(60)$ & 0.02 \\
\hline $\begin{array}{l}\text { Megakaryocytic } \\
\text { hyperplasia, n (\%) }\end{array}$ & $8(100)$ & $35(50)$ & 0.006 \\
\hline Dilated sinusoids, $\mathrm{n}(\%)$ & $6(75)$ & $4(5.7)$ & $<0.0001$ \\
\hline $\begin{array}{l}\text { Reactive lymphoid } \\
\text { nodules, } \mathrm{n}(\%)\end{array}$ & $6(75)$ & $15(21.4)$ & 0.004 \\
\hline
\end{tabular}

Values are mean (SD) percentages, unless otherwise indicated.

Fibrosis, mild or moderate fibrosis (grade 1 or 2). ${ }^{13}$ 


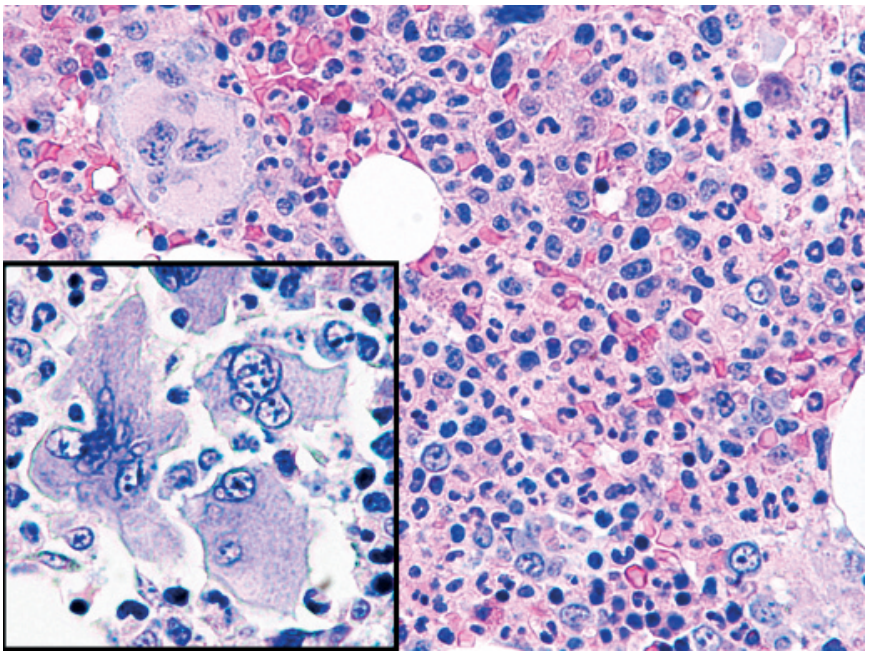

Figure 1 Bone marrow biopsy of a chronic myelomonocytic leukaemia with $\mathrm{JAK} 2^{\mathrm{V} 617 \mathrm{~F}}$ mutation showing marrow hypercellularity, marked myeloid hyperplasia and clustered megakaryocytes (inset) (Dominici stain, original magnification $\times 400$ ).

studies reporting mutations in $3 \%,{ }^{12} 7.8 \%{ }^{10}$ and $13 \%$ of CMML. ${ }^{11}$ Interestingly, JAK2 ${ }^{\mathrm{V} 617 \mathrm{~F}}$ mutation was associated with clinical, haematological and BM morphological features suggestive of a myeloproliferative disease. Indeed, the patients with JAK2 ${ }^{\mathrm{V} 617 \mathrm{~F}}$ mutation all presented with splenomegaly and had significantly higher haemoglobin level, red blood cell and neutrophil count than patients without the mutation.

Furthermore, BM biopsy of CMML with JAK2 ${ }^{\mathrm{V} 617 \mathrm{~F}}$ mutation showed in all cases marked erythroid, myeloid and megakaryocitic hyperplasia, with occasionally large and clustered megakaryocytes. In particular, a mild or moderate fibrosis (grade 1 or 2$)^{13}$ was evident in BM biopsy of all mutated CMML, but in only 13 of 70 non-mutated cases $(p<0.00001)$; an increased number of dilated sinusoids and reactive lymphoid nodules was seen in six of the mutated cases, but in only 4 and 15 of 70 non-mutated cases ( $p<0.0001$ and 0.004 , respectively). These findings are in contrast with those of Steensma et $a l^{12}$

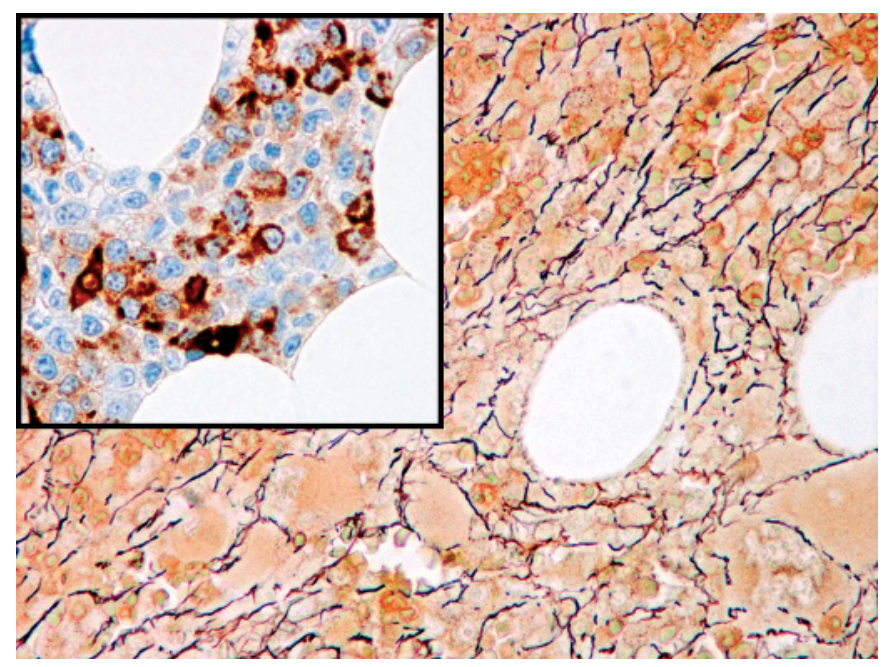

Figure 2 Bone marrow biopsy of a chronic myelomonocytic leukaemia with JAK2 ${ }^{\mathrm{V} 617 \mathrm{~F}}$ mutation showing grade 1 fibrosis (Gomori stain, original magnification $\times 400$ ) and clusters of monocytes (inset, CD68PGM1 immunostaining, original magnification $\times 400$ ).

\section{Take-home messages}

- Chronic myelomonocytic leukaemia (CMML) is a haematopoietic malignancy with heterogeneous clinical and morphological features and is classified in the World Health Organization myeloproliferative-myelodysplastic overlap category. JAK2 ${ }^{\mathrm{V} 617 \mathrm{~F}}$ mutation can be found in a large percentage of myeloproliferative neoplasms.

- All patients with CMML and JAK2 ${ }^{\mathrm{V} 617 \mathrm{~F}}$ mutation displayed splenomegaly with higher haemoglobin level and neutrophil count than patients without the mutation. Bone marrow biopsies of JAK2 ${ }^{\mathrm{V} 617 \mathrm{~F}}$-mutated CMML showed in all cases an increased erythropoiesis, a marked myeloid and megakaryocytic hyperplasia and a mild or moderate fibrosis.

- JAK2 ${ }^{\mathrm{V} 617 \mathrm{~F}}$ mutation is associated with clinical and morphological features of the myeloproliferative type of CMML. Therefore, JAK2 ${ }^{\mathrm{V} 617 \mathrm{~F}}$ mutation analysis together with bone marrow histopathology could help to provide a more appropriate classification of the disease.

who found primarily proliferative features in only one of three patients with JAK2 $2^{\mathrm{V} 617 \mathrm{~F}}$-mutated $\mathrm{CMML}$, and are also partly different from those of Jelinek et a ${ }^{11}$ who reported splenomegaly and megakaryocytic hyperplasia in only three and five of seven CMML patients, respectively. An appropriate classification of CMML is still controversial, and the use of the peripheral white blood cells at diagnosis $\left(\leqslant 13 \times 10^{9} / 1\right)$ as the single criterion for subclassificaton of the disease does not seem fully justified. ${ }^{17}$ Our results indicate that JAK2 $2^{\mathrm{V} 617 \mathrm{~F}}$ mutation is associated with clinical and morphological features of the myeloproliferative type of CMML. Therefore, JAK2 ${ }^{\mathrm{V} 617 \mathrm{~F}}$ mutation analysis together with bone marrow histopathology could help to provide a more appropriate classification of the disease.

Funding: This work was supported by grants from the Italian Ministero dell'Università e Ricerca Scientifica e Tecnologica (MURST).

Competing interests: None.

Ethics approval: Ethics approval was obtained from the Ethics Committee of ASO San Giovanni Battista - ASO CTO/CRF/Maria Adelaide of Turin.

Provenance and peer review: Not commissioned; externally peer reviewed.

\section{REFERENCES}

González-Medina I, Bueno J, Torrequebrada A, et al. Two groups of chronic myelomonocytic leukaemia: myelodysplastic and myeloproliferative. Prognostic implications in a series of a single center. Leuk Res 2002;26:821-4.

2. Cortes J. CMML: a biologically distinct myeloproliferative disease. Curr Hematol Rep 2003;2:202-8.

3. Onida F, Beran M. Chronic myelomonocytic leukemia: myeloproliferative variant. Curr Hematol Rep 2004;3:218-26.

4. Orazi A, Bennett JM, Germing U, et al. Chronic myelomonocytic leukaemia. In: Swerdlow SH, Campo E, Harris NL, et al, eds. WHO classification of tumours of haematopoietic and lymphoid tissues. 4th edn. Lyon: IARC Press, 2008:75-9.

5. Baxter EJ, Scott LM, Campbell PJ, et al. Cancer Genome Project. Acquired mutation of the tyrosine kinase JAK2 in human myeloproliferative disorders. Lancet 2005;365:1054-61.

6. Levine RL, Wadleigh $\mathrm{M}$, Cools J, et al. Activating mutation in the tyrosine kinase JAK2 in polycythemia vera, essential thrombocythemia, and myeloid metaplasia with myelofibrosis. Cancer Cell 2005;7:387-97.

7. James C, Ugo V, Le Couédic JP, et al. A unique clonal JAK2 mutation leading to constitutive signalling causes polycythaemia vera. Nature 2005;434:1144-8.

8. Kralovics R, Passamonti F, Buser AS, et al. A gain-of-function mutation of JAK2 in myeloproliferative disorders. N Engl J Med 2005;352:1779-90.

9. Xiao Z, Zhang Y, Li L, et al. The Janus kinase 2 (JAK2) V617F mutation in Chinese patients with chronic myeloproliferative disorders. Haematologica 2008;93:787-8.

10. Levine RL, Loriaux M, Huntly BJ, et al. The JAK2V617F activating mutation occurs in chronic myelomonocytic leukemia and acute myeloid leukemia, but not in acute lymphoblastic leukemia or chronic lymphocytic leukemia. Blood 2005;106:3377-9. 
11. Jelinek J, Oki Y, Gharibyan V, et al. JAK2 mutation $1849 \mathrm{G}>\mathrm{T}$ is rare in acute leukemias but can be found in CMML, Philadelphia chromosome-negative CML, and megakaryocytic leukemia. Blood 2005;106:3370-3.

12. Steensma DP, Dewald GW, Lasho TL, et al. The JAK2 V617F activating tyrosine kinase mutation is an infrequent event in both "atypical" myeloproliferative disorders and myelodysplastic syndromes. Blood 2005;106:1207-9.

13. Thiele J, Kvasnicka HM, Facchetti F, et al. European consensus on grading bone marrow fibrosis and assessment of cellularity. Haematologica 2005; 90:1128-32.

14. Thiele J, Kvasnicka HM, Schmitt-Graeff A, et al. Bone marrow changes in chronic myelogenous leukaemia after long-term treatment with the tyrosine kinase inhibitor
STI571: an immunohistochemical study on 75 patients. Histopathology

2005; 46:540-50.

15. van Dongen JJ, Macintyre EA, Gabert JA, et al. Standardized RT-PCR analysis of fusion gene transcripts from chromosome aberrations in acute leukemia for detection of minimal residual disease. Report of the BIOMED-1 Concerted Action: investigation of minimal residual disease in acute leukemia. Leukemia 1999;13:1901-28.

16. Dixon WJ, Brown MG, Engelman L, et al. BMPD statistical software manual. Berkeley, CA: University of California Press, 1990.

17. Voglová J, Chrobák L, Neuwirtová R, et al. Myelodysplastic and myeloproliferative type of chronic myelomonocytic leukaemia-distinct subgroups or two stages of the same disease? Leuk Res 2001;5:493-9. 